\title{
In-situ medical simulation for pre-implementation testing of clinical service in a regional hospital in Hong Kong
}

\author{
PP Chen *, Nick TK Tsui, Arthur SW Fung, Alick HF Chiu, Wendy CW Wong, HT Leong, \\ Paul SF Lee, James YW Lau
}

\section{A B S T R A C T}

The implementation of a new clinical service is associated with anxiety and challenges that may prevent smooth and safe execution of the service. Unexpected issues may not be apparent until the actual clinical service commences. We present a novel approach to test the new clinical setting before actual implementation of our endovascular aortic repair service. In-situ simulation at the new clinical location would enable identification of potential process and system issues prior to implementation of the service. After preliminary planning, a simulation test utilising a case scenario with actual simulation of the entire care process was carried out to identify any logistic, equipment, settings or clinical workflow issues, and to trial a contingency plan for a surgical complication. All patient care including anaesthetic, surgical, and nursing procedures and processes were simulated and tested. Overall, 17 vital process and system issues were identified during the simulation as potential clinical concerns. They included difficult patient positioning, draping pattern, unsatisfactory equipment setup, inadequate critical surgical instruments, blood products logistics, and inadequate nursing support during crisis. In-situ simulation provides an innovative method to identify critical deficiencies and unexpected issues before implementation of a new clinical service. Life-threatening and serious practical issues can be identified and corrected before formal service commences. This article describes our experience with the use of simulation in pre-implementation testing of a clinical process or service. We found the method useful and would recommend it to others.

\section{Hong Kong Med J 2017;23:404-10}

DOI: $10.12809 / \mathrm{hkmj} 166090$

\author{
${ }^{1}$ PP Chen *, FHKAM (Anaesthesiology) \\ ${ }^{1}$ NTK Tsui, FHKAM (Anaesthesiology) \\ ${ }^{1}$ ASW Fung, MB, BS \\ AHF Chiu, BScN \\ ${ }^{1}$ WCW Wong, FHKAM (Anaesthesiology) \\ ${ }^{2}$ HT Leong, FHKAM (Surgery) \\ ${ }^{3}$ PSF Lee, FHKAM (Radiology) \\ ${ }^{4}$ JYW Lau, FHKAM (Surgery)
}

1 Department of Anaesthesiology and Operating Services, North District Hospital, Sheung Shui, Hong Kong

2 Department of Surgery, North District Hospital, Sheung Shui, Hong Kong Department of Radiology, North District Hospital, Sheung Shui, Hong Kong

${ }^{4}$ Department of Surgery, Prince of Wales Hospital, The Chinese University of Hong Kong, Shatin, Hong Kong

* Corresponding author: chenpp@ha.org.hk

\section{Introduction}

The implementation of clinical service in a new hospital facility or location is associated with challenges that may prevent a smooth and safe execution of the service. ${ }^{1}$ New equipment, unfamiliar surroundings and setup, untested emergency care support, alarm systems and logistics, and new interdisciplinary staff mix may contribute to unexpected negative outcomes. Anticipated and actual practices may differ significantly and need to be modified to adapt to the new environment. In addition, some unexpected issues may not be apparent until the actual clinical service commences. Such concerns may lead to significant anxiety and stress in both administrative and clinical staff involved in the planning of the new service.

Clinical simulation is commonly employed in education and patient safety training of frontline health care professionals. ${ }^{2}$ It is now becoming increasingly common that simulation is also used in assessment, credentialing, and even in health care system integration and feasibility testing of clinical process and equipment. ${ }^{3,4}$ Advanced simulation methods have previously been adopted to assess and optimise workflow and setup at new facility prior to clinical operation. ${ }^{5,6}$ Usability testing of new equipment with simulation techniques may enhance medical safety before clinical application. In-situ simulation at a new clinical location offers a unique opportunity to identify potential process and system issues prior to implementation of a new service. This type of simulation method is valuable to assess, troubleshoot, or develop new system processes. ${ }^{7}$

Our hospital is a local district hospital with about 480 beds. A new endovascular aortic repair (EVAR) service was planned in the angiography 
suite located in the Department of Radiology on the hospital ground floor. No elective surgical procedure under anaesthesia had previously been performed at this location. This location is remote from the operating theatre suite and intensive care unit that are located on the second floor of the same building. We conducted an in-situ simulation of a clinical case 2 weeks before the first procedure in a real patient to assess the readiness of our preparation for the clinical service.

\section{Definitions}

Simulation is defined as a technique that creates a situation or environment that allows a person to experience a representation of a real event for the purpose of practice, learning, evaluation and testing, or to gain an understanding of systems or human actions. $^{7}$ In-situ simulation refers to simulation exercises that take place in the actual patient care setting/environment in an effort to achieve a high level of fidelity and realism.

\section{Planning a new service}

Effective and safe planning of a new service is not only challenging but often a tedious and fretful procedure. In our case, key stakeholders including the operating theatre nursing team, anaesthesiologists, surgeons, and angiography suite staff met on four occasions over 2 months to discuss the logistics of patient flow, clinical service needs, and setup. Patient selection criteria, preparation, transfer logistics, location setup, equipment, drugs and consumables stocks, and postoperative care were discussed. Workflow logistics; clinical care plans; detailed emergency and contingency plans; and lists of essential surgical, anaesthetic, and nursing consumables and equipment were worked out and agreed by all parties. Several visits to the angiography suites were held to assess the site and familiarise staff. The position of patient and health care staff, equipment, and overall setup were tried out.

At the last planning session, a simulated case was proposed to be performed at the new clinical location to test our preparation before the first real patient case was conducted.

\section{Research approval and informed consent}

Clinical research ethics committee approval was not required as this was a simulated site-testing exercise with no study participant or data involved. All parties involved consented to participate voluntarily, and the project was supported and approved by the Hospital's Chief Executive and the Hospital's Working Group on EVAR service.

\section{Clinical scenario}

In order to facilitate the simulation test, a clinical

\section{本地一所醫院在推行新的臨床服務前進行現場 模擬測試 \\ 曾煥涁、徐子健、馮遂榮、趙克輝、黃翠華、梁慶達、 李醒芬、劉潤皇}

推行新的臨床服務計劃時會面對很多挑戰, 當正式推行時更會出現很 多意想不到的問題, 以至新服務無法順利和安全地推行, 執行的醫護 人員亦會產生焦慮。有見及此, 本院推出新的血管內主動脈修復服務 前, 使用了一種嶄新的方法來測試新的臨床設備。我們利用現場模擬 演習辨識新服務計劃潛在的運作和系統問題。經初步規劃後, 利用個 案情境進行整個過程的模擬測試, 目的在於找出整個流程內任何後 勤、裝置、設備和臨床工作流程上的不足, 並假設有手術併發症的情 況下制定相應的應急計劃。我們對病人的所有護理程序, 包括麻醉 手術和護理過程進行了模擬及測試。整體而言, 模擬過程中我們發現 了17項重要的潛在運作和系統問題, 包括病人定位時遇到的困難、懸 垂模式、裝置及設備欠佳、手術時重要的輔助工具不足、血液製品的 運輸過程, 以及危急時護士支援不足。推行新的臨床服務前, 現場模 擬測試可辨識服務的不足之處以及出乎意料的問題。這樣, 在正式投 入服務時便可預先糾正可威脅病人安全的嚴重問題。本文分享了本院 在推行新的臨床設施或服務前使用現場模擬的經驗。我們發現這方法 成效顯著, 值得推薦。

case scenario was developed by two co-authors (TTK and $\mathrm{WCW}$ ) who are simulation education-trained instructors and were the main coordinators of the exercise. The scenario was of a routine case scheduled for EVAR procedure under general anaesthesia in the angiography suite. The case background involved a 78-year-old man with multiple stable medical conditions including hypertension, history of congestive cardiac failure, chronic renal impairment, and a $7-\mathrm{cm}$ infrarenal abdominal aortic aneurysm scheduled for endovascular aortic surgery. He was on aspirin, metoprolol, lisinopril, amlodipine, and isosorbide dinitrate. Echocardiography assessment had reported a left ventricular ejection fraction of $35 \%$. Blood type and screen, and a postoperative bed in intensive care unit were available before the operation. Premedication with oral N-acetylcysteine, midazolam, and his usual medications was prescribed and administered in the ward prior to transfer to the angiography suite.

The scenario began with patient transferring to the angiography suite by ward staff and on arrival, checking by the angiography suite nurse. Timeout was then performed with the anaesthesiologists, surgeon, and nurse in the angiography suite before the anaesthetic procedure commenced. Invasive arterial pressure monitoring was set up, and the patient was anaesthetised on the transfer trolley before being moved onto the angiography table. An anaesthetic workstation (Primus; Drägerwerk AG \& Co. KGaA, 
TABLE I. Resources involved in the simulation exercise

\begin{tabular}{|c|c|}
\hline Manpower & No. of person(s) \\
\hline Coordinators (simulation education trainers) & 2 \\
\hline Technical support staff & 2 \\
\hline Anaesthesiology specialist & 1 \\
\hline Anaesthesiology resident & 1 \\
\hline Vascular surgeon specialist & 1 \\
\hline Operating theatre nurses & 3 \\
\hline Anaesthetic assistants & 1 \\
\hline Ward nurse & 1 \\
\hline Radiographer & 1 \\
\hline Radiology nurse & 1 \\
\hline Actor-patient (ward nurse) & 1 \\
\hline Observer raters (nursing managers) & 3 \\
\hline Other observers (non-essential) & 5 \\
\hline \multicolumn{2}{|l|}{ Duration of multidisciplinary activity } \\
\hline $\begin{array}{l}\text { Scenario development and design of evaluation } \\
\text { checklist (by coordinators) }\end{array}$ & 10 Hours \\
\hline Briefing & 30 Minutes \\
\hline Simulation exercise & 3 Hours \\
\hline Debriefing and review & 60 Minutes \\
\hline
\end{tabular}

Germany) with Infinity C700 physiological monitor (Drägerwerk AG \& Co. KGaA, Germany) was used for the general anaesthesia. The anaesthesiologist simulated the induction of general anaesthesia on a training simulator with full virtual physiological monitoring. The anaesthetic procedure tested the setup at the head of the 'operating table' and the logistics of delivering anaesthesia to the patient in the small and compact room.

Following general anaesthesia, the surgeon cleaned and draped the surgical field, and commenced the surgical procedure according to his usual practice at another hospital. One nurse scrubbed in and another two circulating nurses assisted the procedure. All required surgical instruments and equipment were laid out on sterile trolleys. The surgical team performed each step of the procedure as in a real clinical case including imitating the femoral arterial puncture and insertion of the guidewire and aortic stent to test the surgical setup, equipment locations, and the positions of staff and patient. No EVAR simulator or manikin was used for the surgical procedure part as we did not intend to assess the technical aspects of the surgical procedure.

When the surgical part of the exercise was completed, the scenario proceeded to evaluate the contingency plan in case of a surgical complication resulting in haemorrhagic shock. The patient would need to be transferred to the operating theatre for open surgery to stop the bleeding, instead of directly to the intensive care unit from the angiography suite after completion of the procedure as per preoperative plan. The surgeon was able to test the availability of surgical instruments for haemostasis while the anaesthesiology team was able to test the logistics, clinical support, and treatment protocols for fluid and blood resuscitation, and urgent arrangements for transferring to the main operating theatre. The site of surgical complication was not specified and the surgeon went through a mental exercise with the surgical team of different surgical management requirements during the crisis.

\section{Simulation exercise}

Two co-authors were responsible for coordinating, directing, and running the exercise. Frontline representatives from the anaesthetic, vascular surgery, operating theatre nursing, and angiography suite teams who will be involved in the new future clinical service were nominated by their heads of department to participate in the simulation exercise. An actor who was a ward nurse played the role of the patient during transfer from the ward to the angiography suite as it facilitated the checking procedure. The patient checking part of the scenario also involved a participant nurse from the surgical ward who accompanied the patient from the ward. The participants involved are shown in Table 1.

A high-fidelity simulator (SimMan 3G; Laerdal, Stavanger, Norway) was used during the perioperative phase from timeout procedure onwards. The SimMan 3G can be controlled by a wireless laptop, and is able to generate virtual vital signs on a monitor. This simulator has peripheral pulses, chest expansion, pupillary responses, and can simulate normal and abnormal breath sounds, heart sounds, pupil size, and normal and difficult airway, among other functions. The entire induction of anaesthesia including tracheal intubation was performed on the simulator. The technical part of the simulation was supported by two staff from the Simulation and Training Centre.

The simulation exercise took place in the afternoon of a normal working day. The area of simulation exercise was an isolated part of the Department of Radiology with minimal patient traffic. A half-hour briefing of involved parties was conducted prior to the commencement of the exercise. The objective of the exercise to test the workflow logistics, setup, and care plans of the new service was explained. All participants were instructed to play their professional role during the simulated exercise, as they would in the real clinical situation (Fig 1). The exercise was carried out in four phases: a pre-anaesthetic phase, anaesthesia induction phase, operative phase, and postoperative phase. 


\section{Data collection and evaluation}

Three observers who were nurse managers from the operating theatre and surgical wards evaluated the

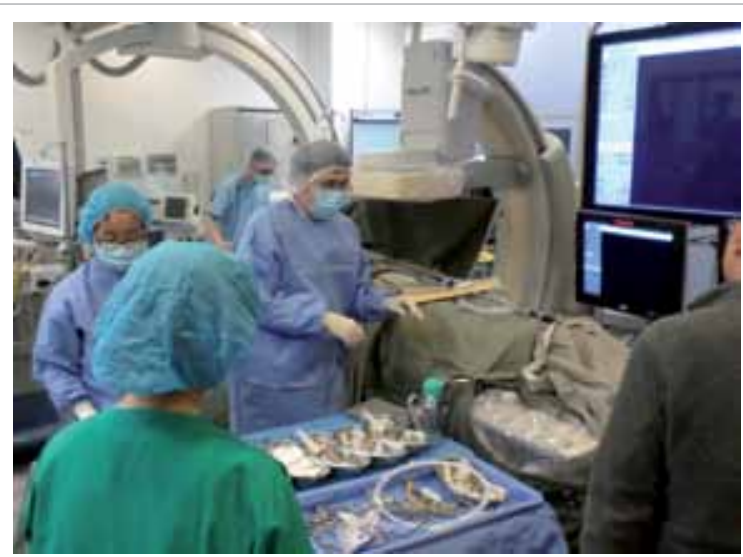

FIG I. Surgeon ready to start scenario and made comments independently. An evaluation checklist was designed by the exercise coordinators together with members of the planning team for observers to identify any deficiency and safety issues associated with the event at each phase (Table 2). The checklist followed the anticipated flow of events during the case. The evaluation began with pre-medication and sending of the patient to the angiography suite. Positioning, surgical draping, range of X-ray table, and blood ordering logistics were tested. After the scenario, all participants were debriefed, and observers were invited to share their observations. Areas of improvement were noted and required alterations made by relevant team members before scheduling first real patient for the EVAR procedure in the angiography suite.

\section{Issues identified}

The in-situ simulation took place in the angiography

TABLE 2. Observer evaluation checklist

\begin{tabular}{|c|c|c|}
\hline Stage & Points to note & Comments \\
\hline \multicolumn{3}{|l|}{ Pre-anaesthetic phase } \\
\hline Transfer to angiography suite & $\begin{array}{l}\text { - Routine patient checking procedure } \\
\text { - Premedications } \\
\text { - Oxygen delivery availability, monitors }\end{array}$ & \\
\hline Angiosuite waiting area & $\begin{array}{l}\text { - Suitability of waiting area } \\
\text { - Monitoring a sedated patient }\end{array}$ & \\
\hline Theatre preparation & $\begin{array}{l}\text { - Equipment preparation } \\
\text { - Angiography suite setup } \\
\text { - CMS/AIS (Information) systems } \\
\text { - Consumables-drugs, fluids, etc } \\
\text { - Any other difficulty encountered }\end{array}$ & \\
\hline \multicolumn{3}{|l|}{ Anaesthesia induction phase } \\
\hline General anaesthesia & $\begin{array}{l}\text { - Time-out procedure } \\
\text { - GA induction on stretcher } \\
\text { - Transfer to angio-table } \\
\text { - Monitoring in control room } \\
\text { - Availability of drugs, equipment } \\
\text { - Positioning on angio-table } \\
\text { - Access to patient } \\
\text { - Lines and breathing circuits }\end{array}$ & \\
\hline \multicolumn{3}{|l|}{ Operative phase } \\
\hline Operation & $\begin{array}{l}\text { - Radiological hazards } \\
\text { - Positions of angio-table, C-arm } \\
\text { - Adequacy of surgical instruments } \\
\text { - Surgical field access } \\
\text { - Surgical team positions }\end{array}$ & \\
\hline Crisis & $\begin{array}{l}\text { - Blood ordering procedure and time } \\
\text { - Crisis management and resuscitation } \\
\text { - Team approach, individual roles } \\
\text { - Urgent OT booking procedure }\end{array}$ & \\
\hline \multicolumn{3}{|l|}{ Postoperative phase } \\
\hline Transfer & $\begin{array}{l}\text { - Logistics of transfer } \\
\text { - Monitors, ventilatory support } \\
\text { - Route of transfer }\end{array}$ & \\
\hline \multicolumn{3}{|c|}{ Other comments (use additional pages if required) } \\
\hline
\end{tabular}

Abbreviations: CMS/AIS = Clinical Management System/Anaesthesia Information System; GA = general anaesthesia; OT = operating theatre 
suite over four phases in 3 hours. During the logistics, and inadequate nursing support during simulation, 17 vital process and system issues were the crisis (Table 3). Some of these deficiencies identified, including anaesthetic and surgical issues were corrected immediately during the simulation such as poor patient positioning, draping pattern, exercise. During the post-exercise, observer unsatisfactory equipment setup, inadequate critical checklist deficiencies and participant experience surgical instruments, blood products requesting were reviewed and discussed, and solutions devised.

TABLE 3. Issues identified (critical issues in italics)

Issues Rectifications

Pre-anaesthetic phase

1. Angiography suite was too crowded for patient checking on arrival

2. There were inadequate electric sockets at the head-end for additional infusion devices

3. The process of checking out opioids was difficult

4. Remifentanil was not available and had to be checked out from the OT

Patient checking should be performed in the waiting area outside the angiography suite

Additional extension boards were acquired to facilitate access to the sockets at the foot-end

The procedure for checking out opioids was reviewed and revised

An arrangement was made with pharmacy to store and dispense remifentanil in the angiography suite

Anaesthetic induction

1. It was found that the angio-table could not be tilted

A tiltable trolley will be parked outside the angiography suite in case of urgent need

2. Access to patient's head and intravenous access difficult due to crowdedness at head-end

3. The rotating $\mathrm{C}$-arm was in the way during induction of general anaesthesia

4. Equipment cables were trapped underneath C-arm

5. Position of infusion pumps had to be close to patient as the extension delivery tubing was too short

6. Arm board to hold adducted arm did not have fixation straps or padding

7. Breathing circuit was too short when angio-table was moved caudad for procedure

8. Cables were lying all over the angiography suite floor leading to a risk of staff tripping

Operative phase

1. Patient exposure during procedure could predispose the patient to hypothermia

2. Position of the intravenous contrast injection gun was suboptimal making it difficult to ensure an adequate sterile field

3. Inadequate draping when angio-table moved maximally caudad contaminating sterile field

4. Unfamiliar access to CMS for ordering blood products in the angiography suite

5. During the intra-operative crisis of haemodynamic instability, the roles of the nurses from different departments were unclear when multiple tasks were urgently required

6. A particular type of vascular clip was not available when requested by surgeon for haemostasis

7. Unclear procedure for collection of blood products from blood bank, eg no one to collect blood products after it was ordered resulting in delay

8. Surgeon needed to book as Category 1 Emergency if case needed to be converted to open procedure in OT suite

Equipment at the head-end was repositioned for better access. Some standby items were moved to another room

The C-arm was pushed all the way back to the wall at the beginning of anaesthesia induction

The position of various equipment and cables were readjusted

The pumps were repositioned and longer extension tubing was made available

A proper arm board with straps was loaned to the angiography suite from OT

A longer breathing circuit was obtained to replace the pre-existing circuit

An anti-tripping board was obtained to be placed over the ground cables to prevent tripping

A warm air blanket was loaned from OT to keep patient warm

The intravenous contrast injection gun position was readjusted to facilitate the surgical team positions

More sterile drapes were made available; a new draping arrangement proposed

The anaesthesiologists and OT nurses were familiarised with the procedure and location of CMS hardware

The roles and task allocation were discussed and clarified among the nurses

The specific vascular clips were obtained from the main operating suite and stocked at the new location

Blood bank was consulted. The nursing team from the surgical ward and operating team worked out an arrangement to facilitate the process

The booking procedure was simplified and the surgical team was familiarised with the process

Postoperative phase

1. Transport and monitoring equipment were not immediately available for transfer of critically ill patient to OT suite

A physiological monitor with pulse oximeter, ECG and NIBP was added. An arterial pressure module was made available.

Abbreviations: CMS = Clinical Management System; ECG = electrocardiography; NIBP = non-invasive blood pressure; OT = operating theatre 


\section{Benefits of simulation testing}

This is the first reported use of simulation for the purpose of testing a new service in Hong Kong. Previous publications have reported the effectiveness of simulation-based methodology to identify process gaps before major institutional change. 5,6 Kobayashi et al ${ }^{5}$ found the utility of simulated patient encounters in testing a new emergency department functions and operational capabilities useful. The trial run also helped in the design of an optimal clinical care environment. In their experience, most issues that arose were not apparent with traditional preparation efforts. Staff also felt more comfortable and confident attending to critical patients in the new facility after participating in simulated scenarios. Bender et $\mathrm{al}^{6}$ evaluated the function of a new neonatal intensive care unit using simulation-based technology and methodology. The exercise involved multidisciplinary stakeholders in two simulated clinical scenarios. They identified 164 latent safety hazards in communication, facilities, supplies, staffing, and training with over $90 \%$ of them resolved at transition to the new facility. They concluded that it provided valuable benefits for system refinement and patient safety. ${ }^{6}$

Issues such as inadequate electrical sockets and equipment electrical cables, breathing circuit too short, and various positioning difficulties were encountered in our simulation exercise despite earlier planning and preparation (Fig 2). One may

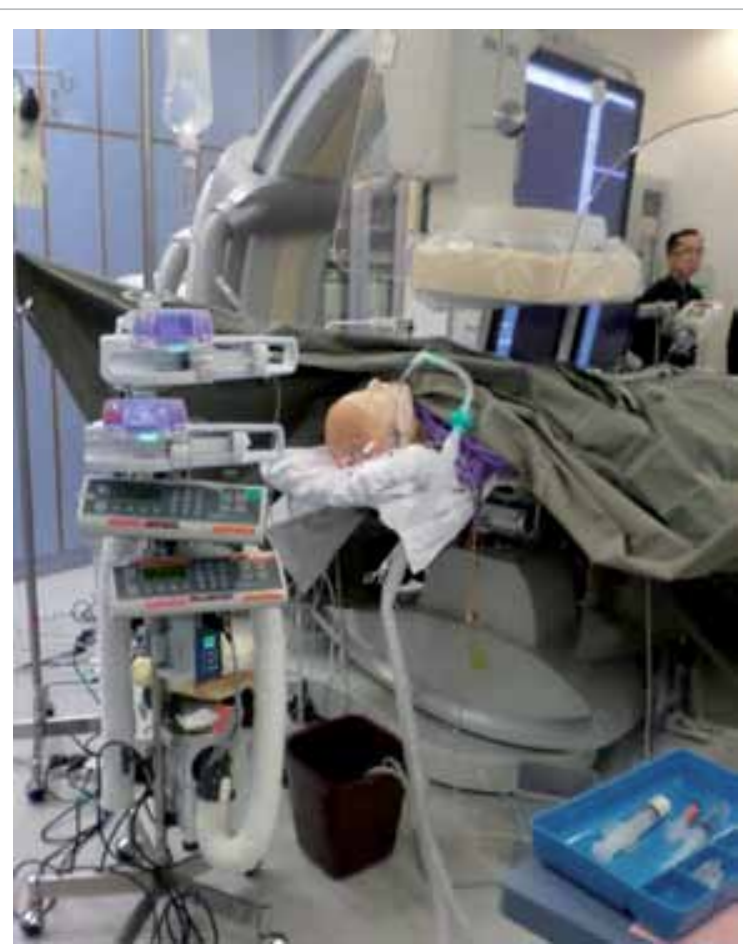

FIG 2. Patient head-end attribute such deficiencies to poor planning in some situations, but simulation testing is in fact a most suitable method to identify and iron out these unanticipated problems, regardless of whether or not they were the result of poor planning. Some issues that may appear trivial and simple to correct were identified as potential patient safety concerns in real life. It was critical that these life-threatening problems and other serious practical issues were identified during the in-situ simulation as this enabled us to make improvements to facilitate a more efficient and safe service. Another example was related to the management of a surgical complication during the procedure, resulting in some urgency for the surgeon to control the bleeding, a sudden and urgent blood request for resuscitation by the anaesthesiologists, and immediate need for emergency surgery in the main theatre suite, all happening simultaneously. An essential surgical vascular clip was found lacking while there was confusion about the logistics of getting blood products requested urgently. Other concerns and difficulties were identified during the crisis and were eventually rectified.

We did not repeat the simulation testing after correcting the deficiencies identified at the initial exercise because of lack of time. We did not feel that it was necessary to repeat the simulation although a second test may still have produced some unexpected results. The first real case therefore became an assessment of the final preparation. The case was conducted 3 weeks after the simulation testing. The procedures at each stage went as anticipated without any problem. The first patient did not require any blood transfusion and we were not able to test the transfusion logistics in real life after simulation testing. In a further subsequent patient (real case) blood transfusion was required, and the logistics of ordering and obtaining blood products urgently were carried out smoothly and uneventfully, indicating successful correction of the initial problems with the blood collection procedure.

\section{Challenges}

A significant amount of time was spent in planning the exercise so that it resembled closely the actual workflow and procedures. As the clinical activity involved several different specialties, it was challenging to organise a multispecialty group to plan and participate in the exercise. The number of participants depends on the usual staffing need of the clinical activity. The two coordinators who were experienced medical simulation trainers were the key persons who devised the scenario and coordinated and executed the simulation exercise. Most participants were required to attend the briefing and simulation exercise only on the day. Some discussions were conducted by email. Although different specialty teams could have 
conducted their own individual exercise separately, the cross-specialty interactions and benefits may not have been apparent.

The leadership of the exercise and the hospital's support were vital for the smooth conduct of the simulation testing. All the heads of department involved in the new service, and our Hospital Chief Executive supported the exercise making it easy to organise the participants and observers.

It is important to test out the actual clinical location. The setting up of the venue required some time prior to the simulation exercise. In our case, the availability of the angiography suite was a challenge as we needed to find an unused session when all stakeholders were also available. This will be especially difficult in a busy hospital where the clinical area may not be available during office hours. In such cases, running the simulation exercise after hours may be considered.

Although in-situ simulation remains an effective method to test out a new location and service, the organiser should ensure that the exercise is not confused with a real clinical case. Special attention should be given to the use of training equipment, drugs, and consumables in the clinical area, so that they are not inadvertently used in a real patient. Staff and other patients in the clinical area should also be aware that the simulation exercise is in progress. It was helpful in our case that the angiography suite was located in an area where patient traffic flow was easily controlled in the afternoon.

In this exercise, we borrowed a high-fidelity human patient simulator from our Simulation and Training Centre. The manikin came with physiological features and computer-controlled virtual vital signs. It was a bonus to have access to this simulator although a successful simulation test such as ours may also be performed with a lower-fidelity manikin such as that used for cardiopulmonary resuscitation training. The advantage for us with this exercise was that the high-fidelity simulator provided real-time temporal changes in vital signs of the patient during the surgical complication, thereby creating a sense of urgency and crisis to the situation. This facilitated the testing of contingency plans during the emergency. The most important aspect of the exercise, however, was not the simulator but the actual role play of the scenario script and evaluation of the settings, workflows logistics, and clinical processes. We were fortunate that technical support from the Centre was also available. In a hospital where such expertise and resources may not be available, this should not be a barrier to simulation-based testing as there is the option to consult a simulation training centre for assistance.

The procedure and results of simulation testing should be clearly documented. One limitation of this study was that we did not document the exercise with video recordings. Photographs were taken but their quality was modest. These would have been helpful in the discussion and sharing process.

\section{Conclusion}

It is advantageous to identify critical deficiencies and unexpected issues that may not be apparent prior to implementation of a new service. The testing of a new clinical service, facility, or environment with simulation technology requires considerable time, effort, and expense. Very often traditional checks and testing will only evaluate individual aspects of a new facility in isolation and separately. Exposing the new environment and critical services to a simulated clinical event allows actual experience of the settings, workflow, and clinical management to reveal issues not apparent with the usual manual checks.

\section{Acknowledgements}

The authors would like to express their appreciation to staff at the Department of Radiology, Department of Anaesthesiology and Operating Services, Department of Surgery, and New Territories East Cluster Simulation and Training Centre for their support and contributions.

\section{References}

1. Berwick DM. A primer on leading the improvement of systems. BMJ 1996;312:619-22.

2. Okuda Y, Bryson EO, DeMaria S Jr, et al. The utility of simulation in medical education: what is the evidence? Mt Sinai J Med 2009;76:330-43.

3. Holmboe E, Rizzolo MA, Sachdeva AK, Rosenberg M, Ziv A. Simulation-based assessment and the regulation of healthcare professionals. Simul Healthc 2011;6 Suppl:S5862.

4. Landman AB, Redden L, Neri P, et al. Using a medical simulation center as an electronic health record usability laboratory. J Am Med Inform Assoc 2014;21:558-63.

5. Kobayashi L, Shapiro MJ, Sucov A, et al. Portable advanced medical simulation for new emergency department testing and orientation. Acad Emerg Med 2006;13:691-5.

6. Bender J, Shields R, Kennally K. Transportable enhanced simulation technologies for pre-implementation limited operations testing: neonatal intensive care unit. Simul Healthc 2011;6:204-12.

7. Healthcare simulation dictionary. Society for Simulation in Healthcare. June 2016. Available from: http://www.ssih. org/dictionary. Accessed Dec 2016. 